\title{
Development of a DNA-Based Real-Time PCR Assay To Quantify Allorhizobium vitis Over Time in Grapevine (Vitis vinifera L.) Plantlets
}

\author{
Trong Nguyen-Huu, ${ }^{1}$ Jeanne Doré, ${ }^{2}$ Essaïd Aït Barka, ${ }^{1}$ Céline Lavire, ${ }^{2}$ Christophe Clément, ${ }^{1}$ Ludovic Vial, ${ }^{2}$ and Lisa Sanchez ${ }^{1, \dagger}$ \\ ${ }^{1}$ Unité EA 4707 Résistance Induite et Bioprotection des Plantes, SFR Condorcet FR Centre National de la Recherche Scientifique \\ (CNRS) 3417, Université de Reims Champagne-Ardenne, Reims, France \\ ${ }^{2}$ UMR Ecologie Microbienne, CNRS, National Research Institute for Agriculture, Food and Environment, VetAgro Sup, Uni- \\ versité Claude-Bernard Lyon, Université de Lyon, F-69622 Villeurbanne, Lyon, France
}

\begin{abstract}
Allorhizobium vitis is the primary causal pathogen of grapevine crown gall disease. Because this endophytic bacterium can survive as a systemic latent (symptomless) infection in grapevine, detecting and monitoring its development in planta is of great importance. In plant bacteria studies, plate counting is routinely used as a simple and reliable method to evaluate the bacterial population level in planta. However, isolation techniques are timeconsuming and present some disadvantages such as the risk of contamination and the need for fresh samples for research. In this study, we developed a DNA-based real-time PCR assay that can replace the classical method to monitor the development of Allorhizobium vitis in grapevine plantlets.

Primers targeting Allorhizobium vitis chromosomic genes and the virulent tumor-inducing plasmid were validated. The proposed quantitative real-time PCR technique is highly reliable and reproducible to assess Allorhizobium vitis numeration at the earliest stage of infection until tumor development in grapevine plantlets. Moreover, this low-cost technique provides rapid and robust in planta quantification of the pathogen and is suitable for fundamental research to monitor bacterial development over time.

Keywords: Agrobacterium, Allorhizobium vitis, grapevine shoots, pathogen detection, real-time PCR
\end{abstract}

Crown gall disease is one of the most important bacterial diseases of grapevine (Vitis vinifera L.) worldwide, leading to a significant yield decrease and, in the worst case, to plant death (Burr et al. 1998; Schroth et al. 1988). The main pathogenic bacterium responsible for this disease is still frequently known under the name Agrobacterium vitis (Ophel and Kerr 1990) but was reclassified in the genus Allorhizobium (Mousavi et al. 2014, 2015). These bacteria are pathogenic only when they carry a tumor-inducing plasmid that harbors all virulence genes required to establish and develop the tumor. Briefly, after plant wound infection by Allorhizobium vitis, the transfer DNA (T-DNA) region of tumor-inducing plasmids is transferred and incorporated into the plant genome, then expressed in the host plant cells (for review, see Gelvin 2017 and Nester 2015). The TDNA oncogenes prompt plant cell division leading to gall development. T-DNA also contains genes for the biosynthesis of a diverse group of metabolites called opines. These molecules serve as a specific nutrient source for Allorhizobium vitis that has corresponding catabolic genes present on tumor-inducing plasmids and therefore play a role in host competition with other bacteria (Gelvin 2017; Nester 2015). Opines are key molecules of tumor-inducing plasmid ecology; consequently, tumor-inducing plasmids are often classified according to opine type synthesis by plant cells. For Allorhizobium

${ }^{\dagger}$ Corresponding author: L. Sanchez; lisa.sanchez@univ-reims.fr

L. Vial and L. Sanchez are co-last authors.

Funding: This work was co-funded by Grand Reims, the European Union ("Europe Invests in Champagne Ardennes") with the European Regional Development Fund ( $\mathrm{PhD}$ grant, AGROVITIFREE project), and the Centre National de la Recherche Scientifique (CNRS) (EC2CO "Ecosphère Continentale et Côtière" CNRS IntEnd).

*The $\boldsymbol{e}$-Xtra logo stands for "electronic extra" and indicates there are supplementary materials published online.

The author(s) declare no conflict of interest.

Accepted for publication 28 July 2020.

(C) 2021 The American Phytopathological Society vitis, the most common types of tumor-inducing plasmids are referenced as nopaline, vitopine, and octopine/cucumopine (Argun et al. 2002; Kuzmanović et al. 2014; Szegedi et al. 1988). Some tumor-inducing plasmids that drive the biosynthesis of both octopine and vitopine were reported, suggesting a possible octopine/vitopine tumor-inducing plasmid (Bini et al. 2008a; Habbadi et al. 2020; Kuzmanović et al. 2018).

Like many pathogenic bacteria, Allorhizobium vitis thrives primarily within its host plant and can sometimes grow in other biotopes or survive in the soil under favorable conditions (Burr and Katz 1983; Schroth et al. 1971; Spiers 1979). In nature, both biotic (e.g., nematodes; Süle et al. 1995) and abiotic (e.g., freezing; Stover et al. 1997) stresses can generate open wounds, which serve as an entrance for the pathogen. This influences the Allorhizobium vitis-mediated infection process and, consequently, the crown gall disease outbreak. Allorhizobium vitis has the capacity to develop endophytically in grapevine (Lehoczky 1968). The bacteria mainly occupy the xylem vessels, which allow them to migrate even to shoot meristems and leaf surfaces (Burr et al. 1998; Johnson et al. 2016). Once established in vineyards, the endophytic bacterium Allorhizobium vitis may persist permanently (Kuzmanović et al. 2018). To control the disease, detecting the presence of the pathogen in grapevine materials and in the soil prior to planting is of strategic importance. For that purpose, PCR-based methods have been developed and have proven high efficacy (Burr et al. 2017), such as PCR with specific primers (Bini et al. 2008a, b; Schulz et al. 1993; Szegedi and Bottka 2002), quantitative real-time PCR (qPCR) (Bini et al. 2008a; Ferrigo et al. 2017), magnetic capture hybridization qPCR (MCH) (Johnson et al. 2013, 2016; Orel et al. 2017), and digital droplet PCR (ddPCR) (Voegel and Nelson 2018). Among these methods, ddPCR (the latest developed) allows direct absolute quantification of the Allorhizobium vitis population; however, compared with $\mathrm{qPCR}$, ddPCR requires more time to set up, is more expensive, and is not routinely used thus far (Voegel and Nelson 2018).

In basic research, precisely quantifying pathogen populations in planta during the infection process under controlled conditions is critical to evaluate the response of the plant to a known amount of pathogen, determine the colonization profile (e.g., mutant strains compared with wild-type strains), or screen the efficiency of potential biological control agents. Classically, for fundamental investigations on plant-bacteria interactions, plate counting is used as a simple 
method for the quantification of bacteria in plant samples. During this process, bacterial cells are extracted from plant tissues and plated on appropriate media in a serial dilution to determine the number of viable bacterial cells as the quantity of CFUs per plant biomass. Nevertheless, this procedure presents some disadvantages (Ross and Somssich 2016). Indeed, a well-defined approach during sampling is needed because of the heterogenic distribution of microorganisms in their hosts and their low quantity in asymptomatic plants. In addition, collected samples cannot be stored and must be processed immediately to ensure the accuracy of the living bacterial populations inside or on the samples. These barriers limit the possibility of measuring very low levels of bacteria or analyzing short-interval time points. Moreover, the plate counting method is labor intensive and requires a sufficient number of replicates because it is vulnerable to repetitive technical mistakes during sample collection, serial dilution pipetting, or colony counting on Petri dishes.

To characterize the colonization profile of the pathogenic bacterium at different stages of infection more carefully and to further rapidly test the efficacy of some biological control agents, we developed a pathosystem with grapevine plantlets/Allorhizobium vitis strain $\mathrm{S} 4$ (AvS4) under controlled conditions in the laboratory. This study aimed to compare two methods of quantification plate counting versus qPCR in this pathosystem. For this purpose, we used a previously known primer pair (virD59 targeting virD2; Bini et al. 2008a) and we defined new primer pairs targeting either virD3 on tumor-inducing plasmids that displayed the largest diversity of conserved vir genes (Vogel and Das 1992) or specific Allorhizobium vitis chromosomic genes (genes present in all strains of this species but absent in other species).

We here propose an optimized qPCR analysis of Allorhizobium vitis quantification and show that this DNA-based method can replace the conventional plate counting assay to monitor Allorhizobium vitis growth in grapevine plantlets, from the early stage of infection (before symptom emergence) until tumor development.

\section{Materials and Methods}

Microorganisms. All bacterial strains used in this study are listed in Supplementary Table S1. Allorhizobium vitis strains were cultivated overnight in mannitol-glutamate (MG) liquid medium (Keane et al. 1970) at $28^{\circ} \mathrm{C}$ and 180 revolutions per minute (rpm). Other bacteria species were cultivated overnight at $180 \mathrm{rpm}$ in King's B liquid medium (King et al. 1954) at $28^{\circ} \mathrm{C}$ except Escherichia coli K12, which was cultivated at $37^{\circ} \mathrm{C}$.

Plant infection. Plantlets of $V$. vinifera 'Chardonnay' were micropropagated as described in Ait Barka et al. (2006). Five-week-old in vitro plantlets were transferred and grown on soil in Magenta boxes under a $16-\mathrm{h} / 8$-h day/night photoperiod at $26^{\circ} \mathrm{C}$ for 1 additional week before infection with $A v \mathrm{~S} 4$. For infection experiments, after overnight growth in MG medium, $A v \mathrm{~S} 4$ cells were collected after centrifugation at $4,500 \times g$ at $4^{\circ} \mathrm{C}$ for $15 \mathrm{~min}$ and washed twice with sterile phosphate-buffered saline (PBS; $10 \mathrm{mM}, \mathrm{pH}$ 6.5). The bacteria concentration was determined by spectrophotometry $(600 \mathrm{~nm})$ and adjusted in PBS to $10^{9} \mathrm{CFU} / \mathrm{ml}\left(\mathrm{OD}_{600}=1.0\right.$ in PBS$)$. The shoots of grapevine plantlets were wounded with a sterile surgical blade and inoculated with the $A v \mathrm{~S} 4$ suspension.

DNA extraction. Genomic DNA (gDNA) was extracted from $1 \mathrm{ml}$ of bacterial culture suspension or $40 \mathrm{mg}$ of plant powder (ground in liquid nitrogen), using the Wizard Genomic DNA Purification Kit Protocol (Promega, Madison, WI) according to the manufacturer's instructions. DNA sample concentration and quality was measured with NanoDrop Microvolume spectrophotometers and fluorometers and visualized by migration in $1 \%$ agarose gel. Extracted DNA was stored at $-20^{\circ} \mathrm{C}$ until use.

Primer design and specificity test. To develop the qPCR method to quantify Allorhizobium vitis, four original primer pairs were designed based on the genome sequence of $A v \mathrm{~S} 4$ (GenBank CP000633 through CP000639; Slater et al. 2009) using PrimerBLAST (Ye et al. 2012), except for virD59 designed according to Bini et al. (2008a) (Table 1). The level of specificity of each primer was checked in silico against the currently known sequences using the Nucleotide Collection Database and the Whole-Genome Shotgun
Contigs Database with Nucleotide blast (https://blast.ncbi.nlm.nih. gov/Blast.cgi) and with Primer-blast (https://www.ncbi.nlm.nih. gov/tools/primer-blast/). Next, the primers were tested empirically in qPCR with DNA extracted from different bacterial culture suspensions.

qPCR. For qPCR, each well contained $50 \mathrm{ng}$ of template DNA, $0.14 \mu \mathrm{M}$ of each specific forward and reverse primer, and $7.5 \mu \mathrm{l}$ of ABsolute Blue SYBR Green ROX (Thermo Scientific) in a total volume of $15 \mu$ l. Reactions were performed with the CFX96 Touch Real-Time PCR Detection System (Bio-Rad) under the following thermal cycle protocol. Samples were preheated to $95^{\circ} \mathrm{C}$ for $15 \mathrm{~min}$. Then, 35 amplification cycles were run: $95^{\circ} \mathrm{C}$ for $10 \mathrm{~s}$ and $60^{\circ} \mathrm{C}$ for $45 \mathrm{~s}$. Fluorescence $(521 \mathrm{~nm})$ was measured at the end of each cycle. After the last amplification cycle, melting curves were acquired by slowly heating from 65 to $95^{\circ} \mathrm{C}$ at $0.1^{\circ} \mathrm{C}$ per second with continuous measurement of fluorescence at $521 \mathrm{~nm}$. The threshold to determine quantification cycle $(\mathrm{Cq})$ values was set at 60 relative fluorescence units for all primers. Two technical replicates were performed for each sample from all experiments.

Phylogenetic analysis. The phylogeny of all bacteria used in this study was inferred from the recA gene retrieved from the NCBI database. For Allorhizobium vitis strains, one recA sequence (named avi1 to avi11) was selected for each $r e c A$ allele as defined by Habbadi et al. (2020) and was complemented with the recA sequence from all Allorhizobium vitis sequenced genomes available in the database. Sequences were aligned using the Clustal $\omega 2$ program within the SeaView 4 package (Gouy et al. 2010). Neighbor-joining and maximum likelihood methods were performed by using the SeaView graphical user interface (http://doua.prabi.fr/software/seaview) with parameters as described by Habbadi et al. (2020).

Primer limits of bacterial detection in vitro. To primarily determine their limit of $A v \mathrm{~S} 4$ detection, primers were tested on a 10 -fold serial dilution of pure $A \nu \mathrm{S} 4 \mathrm{gDNA}$, from $50 \mathrm{ng}$ to $0.05 \mathrm{pg}$, either spiked or not with a background of $50 \mathrm{ng}$ of pure gDNA of grapevine. Next, the limit of detection of primers was further tested in terms of $A v \mathrm{~S} 4$ cells per weight of plant tissue. For this purpose, sterile fresh shoot tissue was collected from 6-week-old in vitro plantlets and ground carefully in liquid nitrogen with sterile pestles and mortars into a fine powder. The suspension of $10^{9} \mathrm{AvS} 4 \mathrm{CFU} / \mathrm{ml}\left(\mathrm{OD}_{600}=1.0\right.$ in PBS) was diluted 10-fold in sterile PBS to obtain a serial dilution from $10^{8}$ to $10^{2} \mathrm{CFU} / \mathrm{ml}$. Then, every $30 \mu \mathrm{l}$ of each concentration was added to $30 \mathrm{mg}$ of sterile fine powder of shoot tissue, resulting in a series of concentrations ranging from $10^{5}$ to $10^{-1} \mathrm{CFU}$ per milligram of plant fresh weight ( $A v \mathrm{~S} 4 \mathrm{CFU} / \mathrm{mg} \mathrm{FW})$. Sterile plant shoot powder with no $A v \mathrm{~S} 4$ was used as the control. The gDNA of all mixtures was then extracted as mentioned previously. This experiment was independently repeated three times with two replicates for each repetition.

In planta bacterial quantification. To monitor the in planta growth of $A v \mathrm{~S} 4$, the shoots of grapevine plantlets were wounded with a sterile surgical blade and inoculated with $3 \mu \mathrm{l}$ of the $A \nu \mathrm{S} 4$ suspension at $10^{9}, 10^{7}$, and $10^{5} \mathrm{CFU} / \mathrm{ml}$ corresponding to the final quantities of $3.10^{6}, 3.10^{4}$, and $3.10^{2} \mathrm{CFU}$, respectively. At 7 days postinfection (dpi), 1-cm-long shoot segments around the infection point were collected for the plate counting and qPCR assays. For the plate counting method, three replicates of three shoot segments $(n=9)$ were weighed and ground in $1 \mathrm{ml}$ of sterile PBS with sterile pestles and mortars. The homogenates were diluted 10-fold and cultured on MG medium. The number of $A v \mathrm{~S} 4$ colonies was counted after 2 days of incubation at $28^{\circ} \mathrm{C}$. For qPCR, DNA extraction of the other two replicates of three shoot segments $(n=6)$ was realized with the Wizard Genomic DNA Purification Kit as mentioned previously. Two independent biological repetitions were done.

Next, to monitor bacteria growth over time in planta, shoots of grapevine plantlets were infected with $3 \mu \mathrm{l}$ of the $A v \mathrm{~S} 4$ suspension at $10^{5} \mathrm{CFU} / \mathrm{ml}$ (corresponding to $3.10^{2} \mathrm{CFU}$ inoculated). For each time point $(1,3,7,14$, and $21 \mathrm{dpi})$, three replicates of three shoot segments $(n=9)$ were collected to quantify the bacterial populations by plate counting and three replicates of three shoot segments $(n=9)$ were collected for qPCR. Three independent biological repetitions were done. 
Statistical analysis. Results were statistically analyzed with SPSS Statistics 20 software. A linear regression analysis was performed to assess a possible relationship between $A v \mathrm{~S} 4$ DNA quantity and $\mathrm{Cq}$ values, the number of $A v \mathrm{~S} 4 \mathrm{CFU}$ infected, and the log ( $A v \mathrm{~S} 4 \mathrm{CFU} /$ $\mathrm{mg} \mathrm{FW})$. Significant differences in the $\log (A v \mathrm{~S} 4 \mathrm{CFU} / \mathrm{mg} \mathrm{FW})$ and $\mathrm{Cq}$ values were analyzed using multiway analysis of variance and the post hoc Tukey test with a 95\% confidence level $(P<0.05)$.

\section{Results}

Primer specificity. To develop a qPCR-based method for Allorhizobium vitis quantification, four original primer pairs were designed and a primer pair (virD59F and virD59R) already used to detect Allorhizobium vitis was also included (Table 1). A recA phylogeny was determined in order to have a general view of Allorhizobium vitis diversity and the relatedness of Allorhizobium vitis strains with other species used in this study (Supplementary Fig. S1). Primers were initially tested in silico before empirical testing with DNA extracted from bacteria that belonged to the genus Allorhizobium (Allorhizobium undicola LMG11875 and Allorhizobium taibaishanense LMG27055), were phylogenetically close to Allorhizobium vitis (Agrobacterium tumefaciens C58, Rhizobium rhizogenes K84, Ensifer meliloti 1021), or were phylogenetically more distant (Burkholderia thailandensis E264, Pseudomonas brassicacearum NFM421, Escherichia coli K12) (Supplementary Fig. S1). In qPCR, primers did not cross with the grapevine DNA but gave signals when tested with samples of grapevine shoot infected with $A v S 4$ (Cq » 19) (Supplementary Fig. S2).

For all primers, an early amplification $(\mathrm{Cq} \approx 12)$ could only be observed with samples containing Allorhizobium vitis DNA (Supplementary Fig. S2). Moreover, primers targeting chromosomal genes, Avi_1889 and Avi_5072, allowed detection experimentally of all tested Allorhizobium vitis strains (Fig. 1). Indeed, avi_1889 and avi_5072 were conserved among Allorhizobium vitis strains, but these genes were not present in the other bacteria even in the other Allorhizobium species such as Allorhizobium undicola and Allorhizobium taibaishanense (Supplementary Figs. S2 and S3). Primers targeting chromosomal genes were also tested in silico against all Allorhizobium vitis whole-genome sequences. In silico analysis suggested that these primers detected the majority (but not all) of Allorhizobium vitis strains (Supplementary Fig. S3). For CT1-2 and KT1-1 strains with primer targeting avi_5072, we detected amplification $(\mathrm{Cq} \approx 12)$ despite the presence of one primer-template mismatch (Supplementary Figs. S2 and S3).

Primers targeting the virulence genes on tumor-inducing plasmids were also developed. The primer sets virD59 and virD3, targeting
virD2 and virD3, respectively, detected mainly vitopine strains (e.g., Allorhizobium vitis $\mathrm{S} 4$ strain) $(\mathrm{Cq} \approx 12$; Fig. 1$)$ but also other strains such as KT1-1, ET2-10, BT2-2, and BT3-1 to a lesser extent $(\mathrm{Cq} \approx 24)$. By using virD3, we developed primers (named virD3cons) to detect both vitopine strains (e.g., Allorhizobium vitis S4, BT3-1), octopine/cucumopine strains (e.g., Allorhizobium vitis KFB264), and octopine/vitopine strains (e.g., Allorhizobium vitis BT2-2, ET2-10, KT1-1, CT1-2) (Fig. 1). However, for virD59, virD3, and virD3cons, a latter amplification $(\mathrm{Cq} \approx 23$ to 25$)$ was observed for Agrobacterium tumefaciens C58, B. thailandensis E264, and Ensifer meliloti 1021 (Supplementary Fig. S2).

Primer limit of detection. All primers tested using a 10-fold dilution series of pure $A v \mathrm{~S} 4$ DNA could amplify until $0.5 \mathrm{pg}$ of pure DNA of $A v \mathrm{~S} 4$ (Fig. 2). For lower template concentrations or the water control, no signal or only unspecific products were noticed according to the melting curves obtained for each primer pair (Table 1). In addition, when mixed with background grapevine DNA, primers were able to detect until a 1:100,000 AvS4:grapevine DNA ratio. The linear trendlines of all primers obtained correlated with those of pure $A v \mathrm{~S} 4$ template DNA, proving no inhibition effect of the plant DNA matrix on primer activity (Fig. 2).

Furthermore, to determine the detection threshold in planta, the qPCR results showed a highly linear correlation $\left(R^{2}>0.98\right)$ between the $\mathrm{Cq}$ values and the $\log (\mathrm{AvS} 4 \mathrm{CFU} / \mathrm{mg} \mathrm{FW})$ for all primers tested (Fig. 3). The lowest limit of detection of all primers was $1.10^{2} \mathrm{AvS} 4$ CFU/mg FW. For lower-quantity and no-template control wells, no signal or unspecific products were observed.

In planta bacterial quantification. To monitor $A v \mathrm{~S} 4$ growth on grapevine (Fig. 4A), we compared the conventional plate counting method (Fig. 4B) with qPCR analysis (Fig. 4C). Results at 7 dpi showed that the qPCR method gave similar quantification profiles compared with the plate counting method (Fig. 4D; Supplementary Fig. S4) $\left(R^{2}>0.98\right)$, meaning that the hereby optimized qPCR method can monitor the $A \nu \mathrm{S} 4$ population in grapevine.

Bacterial quantification over time. To monitor bacterial growth in planta over time, the bacterial populations were measured by the two methods at $1,3,7,14$, and 21 dpi. Morphologically, until 7 dpi, only slight swelling at the wounding sites on grapevine shoots was observed. Tumors started to appear later and steadily developed until the end of the experiment (Fig. 5A). The bacterial populations increased significantly and reached a peak at $3 \mathrm{dpi}\left(10^{6} \mathrm{CFU} / \mathrm{mg}\right.$ FW). They remained stable until 7 dpi before decreasing steadily at 14 and $21 \mathrm{dpi}$ (around $10^{5} \mathrm{CFU} / \mathrm{mg} \mathrm{FW}$ ) (Fig. 5B). The results from qPCR with the five primer pairs also showed the same profile as the plate counting method (Fig. 5C; Supplementary Fig. S5). Plotting the

Table 1. Primers used in this research

\begin{tabular}{|c|c|c|c|c|c|c|}
\hline Primer $^{\mathbf{Z}}$ & Sequence $\left(5^{\prime}\right.$ to $\left.3^{\prime}\right)$ & Target & $\begin{array}{l}\text { Target } \\
\text { length } \\
\text { (bp) }\end{array}$ & Locus & $\begin{array}{c}\text { Melting } \\
\text { temperature } \\
\text { curve peak }\left({ }^{\circ} \mathrm{C}\right)\end{array}$ & Reference \\
\hline $\begin{array}{l}\text { Avi_1889 } \\
\text { FOR }\end{array}$ & TTCTGCATCGACCCGGAAAT & $\begin{array}{l}\text { avsI, acyl homoserine lactone synthase } \\
\text { (avi_1889) }\end{array}$ & 156 & CP000633 & 85 & This study \\
\hline $\begin{array}{l}\text { Avi_1889 } \\
\text { REV }\end{array}$ & GCGAAACATCCGCTCCAAAA & & & & & \\
\hline $\begin{array}{l}\text { Avi_5072 } \\
\text { FOR }\end{array}$ & CGTCTGGCTGATCTTGGGTT & Hypothetical protein (avi_5072) & 185 & CP000634 & 87 & This study \\
\hline $\begin{array}{l}\text { Avi_5072 } \\
\text { REV }\end{array}$ & GATTGATCGCTTCCTCCGCT & & & & & \\
\hline virD59 FOR & ATTGGAATATCTGTCCCG & virD2 virulence gene & 96 & CP000637 & 82.5 & $\begin{array}{l}\text { Bini et al. } \\
(2008 \mathrm{a})\end{array}$ \\
\hline virD59 REV & GGCGAGATCGCGGATATT & & & & & \\
\hline virD3 FOR & GGTGATGGTCCAGCATCCAA & virD3 virulence gene & 112 & CP000637 & 82.5 & This study \\
\hline virD3 REV & AAGCCAAACATTTTCCGCCC & & & & & \\
\hline $\begin{array}{l}\text { virD3cons } \\
\text { FOR }\end{array}$ & AATCCGGAGGTGATGGT & virD3 virulence gene & 149 & CP000637 & 83.5 & This study \\
\hline $\begin{array}{l}\text { virD3cons } \\
\text { REV }\end{array}$ & GGCGTCATGTAAGCGTTG & & & & & \\
\hline
\end{tabular}

${ }^{\mathrm{z}}$ Avi $=$ Allorhizobium vitis, FOR $=$ forward, and $\mathrm{REV}=$ reverse. 
data of both methods in the same graphs resulted in a highly linear correlation with $R^{2}>0.98$, meaning that these two methods are highly comparable (Fig. 5D; Supplementary Fig. S5).

\section{Discussion}

Allorhizobium vitis is an endophytic pathogenic bacterium that can systemically infect grapevine. Quantification of bacterial populations is essential to study their interactions with plant hosts, especially in the case of endophytic bacteria. Several studies used an "artificial" inoculation of the pathogenic bacterium under controlled conditions to monitor population dynamics in planta, deeper investigate the impact of pathogenic strains on plants, or test potential molecules or biological control agents (Hao et al. 2018; Jung et al. 2016; Kaewnum et al. 2013; Kawaguchi 2014). Most of these studies used the fastidious classical plate counting method to determine the level of pathogenic bacteria in different grapevine tissues. Although many studies have developed primers to identify or detect the pathogenic bacteria in infected or asymptomatic tissues (Bini et al. 2008a, b; Schulz et al.
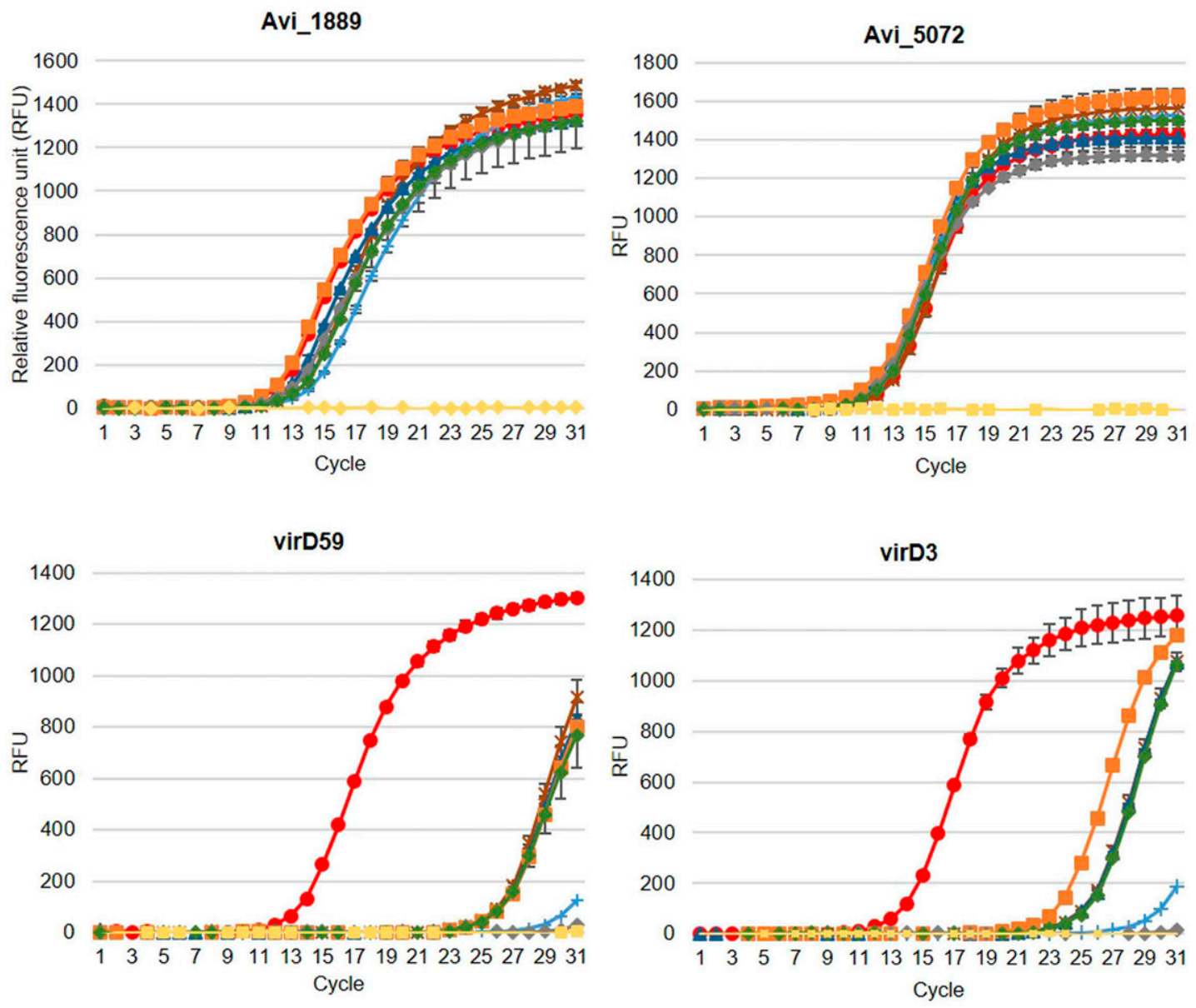

virD3cons
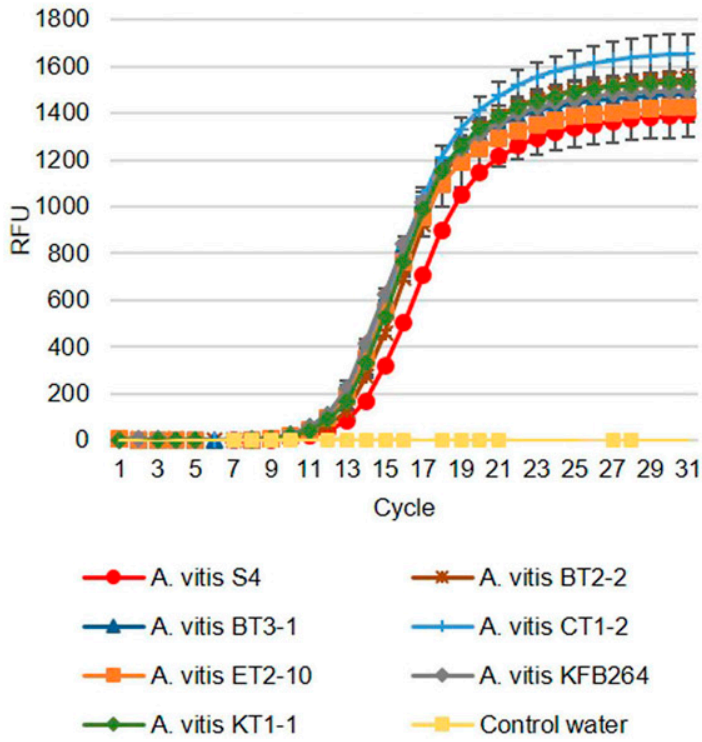

Fig. 1. Primer specificity among seven Allorhizobium vitis strains. Primers targeting chromosomic genes (Avi_1889 and Avi_5072) and the tumor-inducing plasmids (virD59, virD3, and virD3cons) were tested on genomic DNA extracted from different Allorhizobium vitis strain culture suspensions (S4, BT2-2, BT3-1, CT1-2, ET2-10, KFB264, and KT1-1) and a no-template (water) control. The experiment was done with two technical replicates. Error bars represent the SD. RFU = relative fluorescence unit. 
1993; Szegedi and Bottka 2002), few have compared culturedependent enumeration and qPCR (Bini et al. 2008a). qPCR is a widespread method used in numerous pathosystems to detect and quantify microorganisms in the interaction with their hosts (Abdullah et al. 2018; Brouwer et al. 2003; Gachon and Saindrenan 2004; Martin et al. 2000; Weßling and Panstruga 2012). This technique provides less variability compared with culturing-dependent methods (Li et al. 2008; Llorente et al. 2010).

Here, we compared this alternative DNA-based approach and the classical plate counting method to quantify in planta Allorhizobium vitis $\mathrm{S} 4$ populations after artificial inoculation on grapevine plantlets shoots in the laboratory. We used one primer pair for virD59
Avi_1889
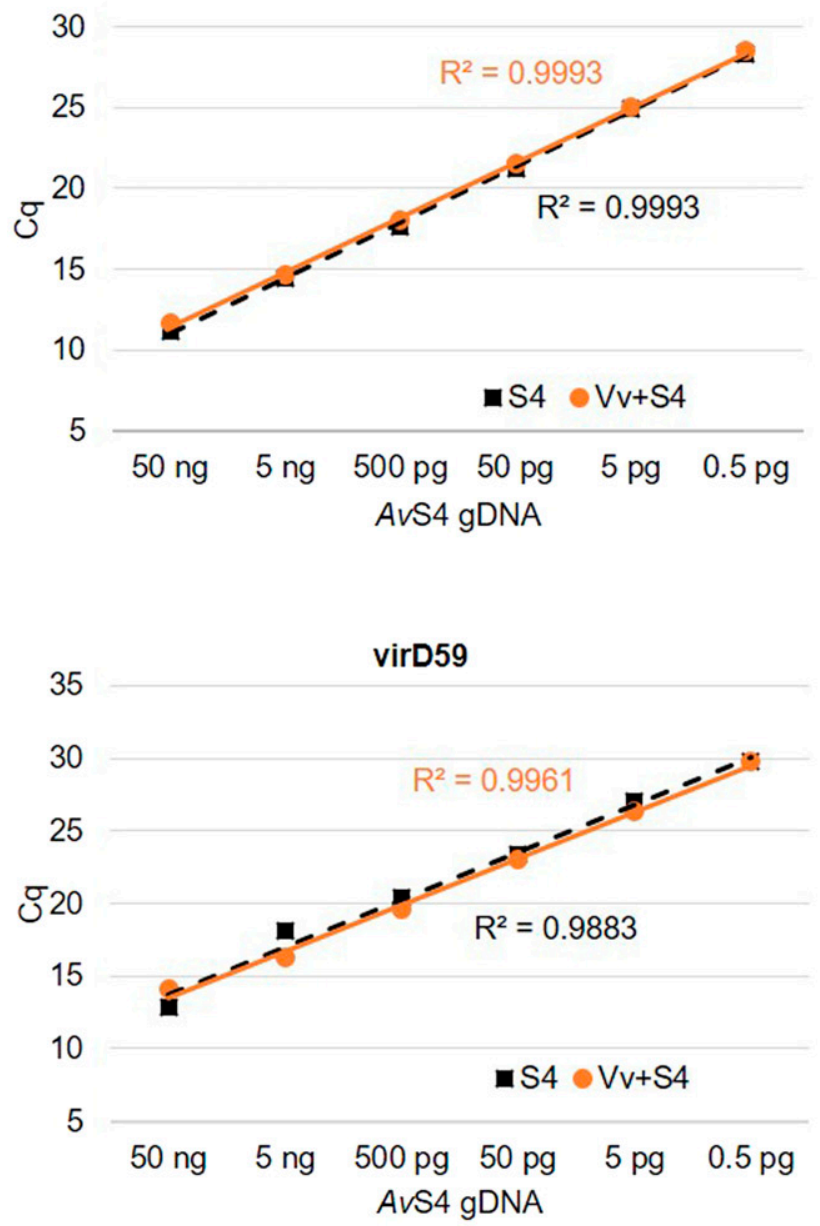

Avi_5072

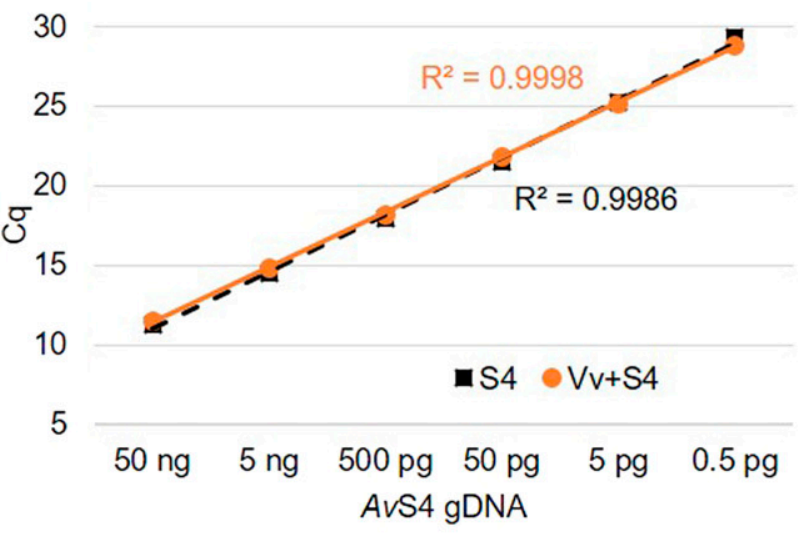

virD3

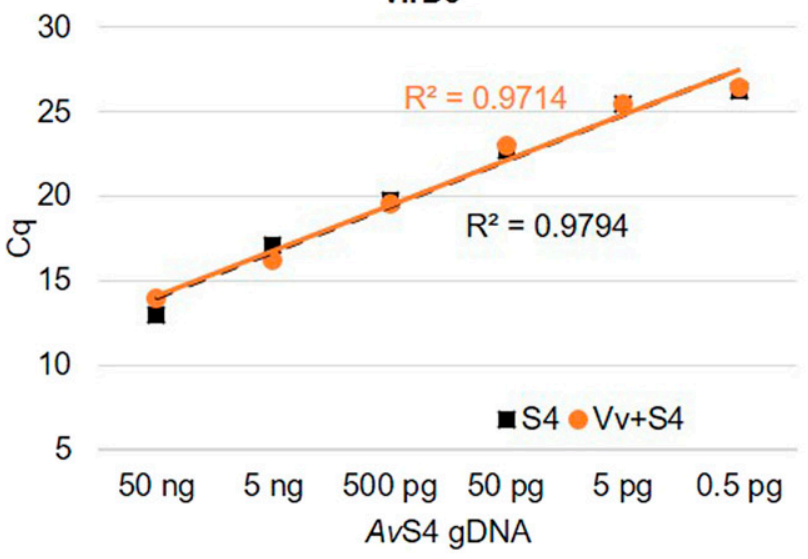

virD3cons

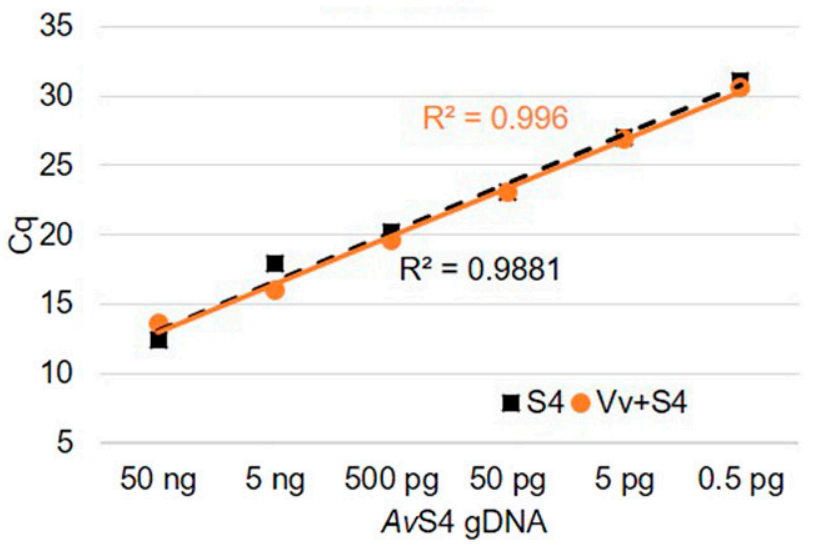

Fig. 2. Primer validation for quantification of genomic DNA (gDNA) of Allorhizobium vitis strain S4 (AvS4). Black squares indicate DNA extracted from the AvS4 culture suspension (S4), and orange circles indicate a mixture of DNA extracted from the AvS4 culture suspension and from the grapevine Vitis vinifera plant (Vv+S4). Correlation coefficients $\left(R^{2}\right)$ are indicated with the corresponding color of each dataset. Linear regressions were obtained with two technical replicates for each primer pair. The lower limit of the linear range determined the limit of quantification. $\mathrm{Cq}=$ quantification cycle. 
described previously (Bini et al. 2008a), and we also developed primers based on the genome sequence of $A v \mathrm{~S} 4$ (Fig. 1) targeting both chromosomic genes and virulence genes on tumor-inducing plasmids. The two primer pairs targeting chromosomal genes (avi_ 1889 and avi_5072) allowed us to exclusively detect Allorhizobium vitis strains tested. Allorhizobium vitis strains can be classified according to the types of opines that their tumor-inducing plasmids produce (Habbadi et al. 2020; Kuzmanović et al. 2018). In this study, we chose seven Allorhizobium vitis strains representing vitopine-, octopine/cucumopine-, and octopine/vitopine-type tumor-inducing plasmids. We worked on three primer pairs targeting the vir region of these three types of tumor-inducing plasmids. The virD3cons primers, targeting a consensus sequence among all three types of tumorinducing plasmids, proved their ability to amplify all Allorhizobium

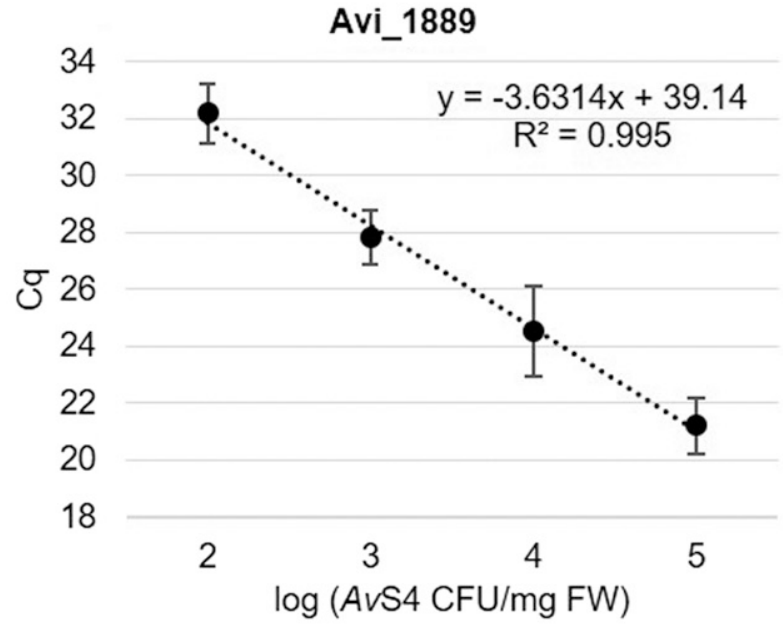

virD59

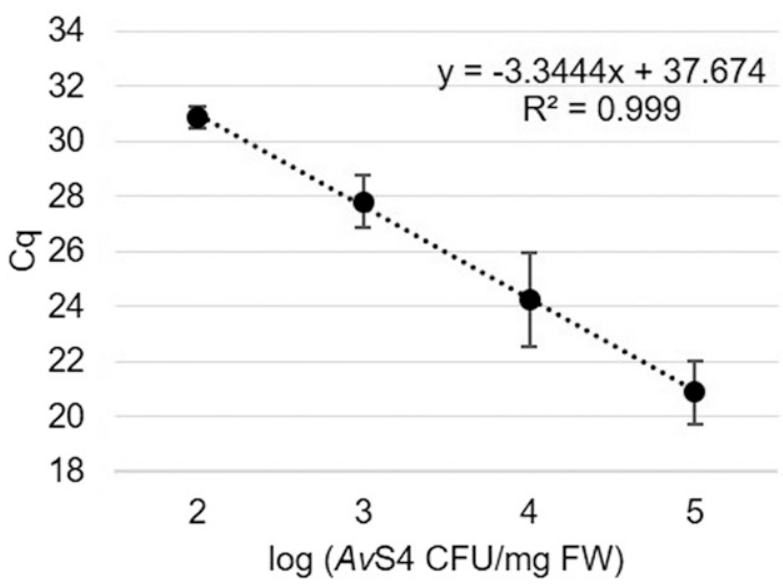

Avi_5072
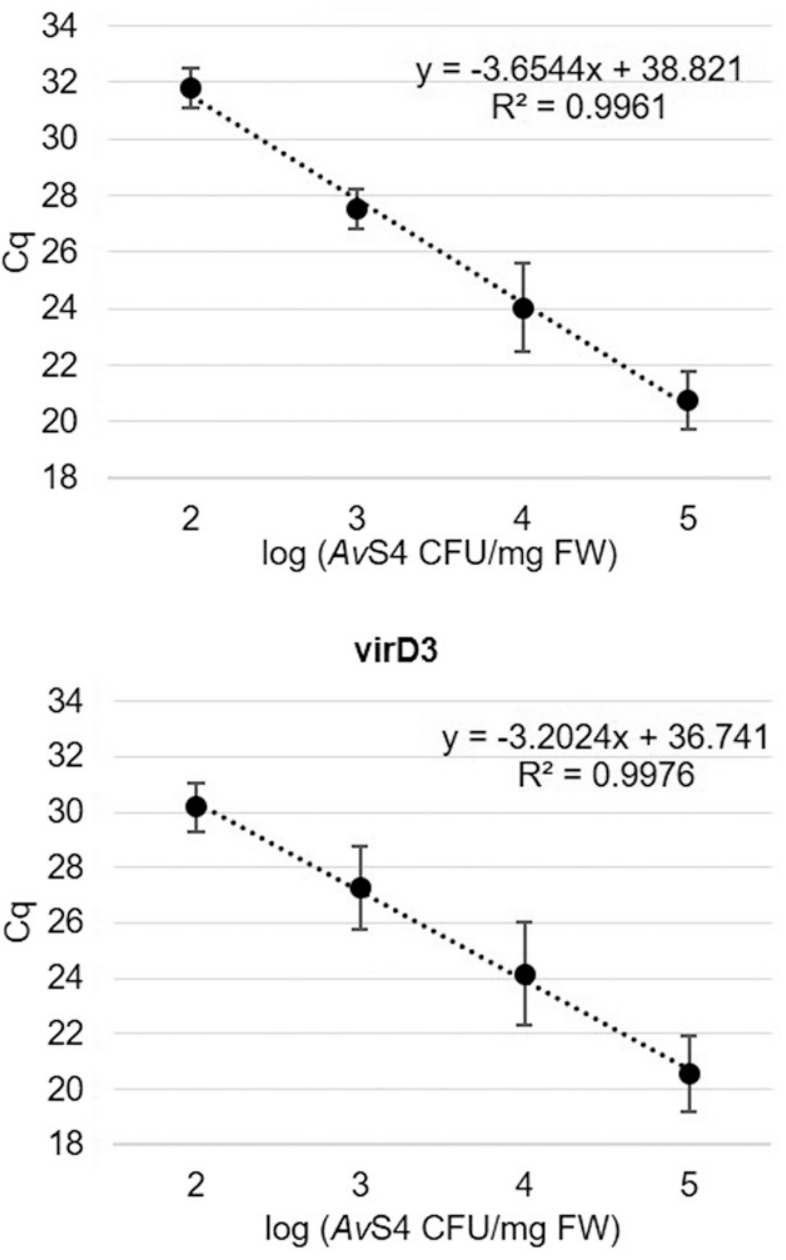

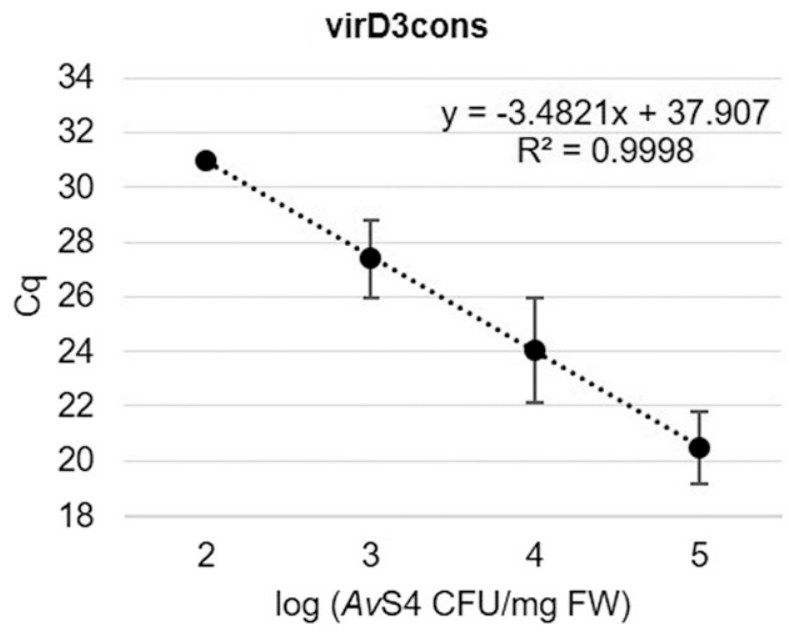

Fig. 3. Limit of detection of primers for quantification of Allorhizobium vitis strain S4 (AvS4) cells in planta. Correlation coefficients $\left(R^{2}\right)$ are indicated. Linear equations demonstrate the relation between the quantification cycle $(\mathrm{Cq})$ value and the bacterial quantity for each primer pair. Data represent means $\pm \mathrm{SD}$ of three biological repetitions realized in duplicate $(n=6)$ for each primer pair. The lower limit of the linear range determined the limit of quantification. FW $=$ fresh weight. 

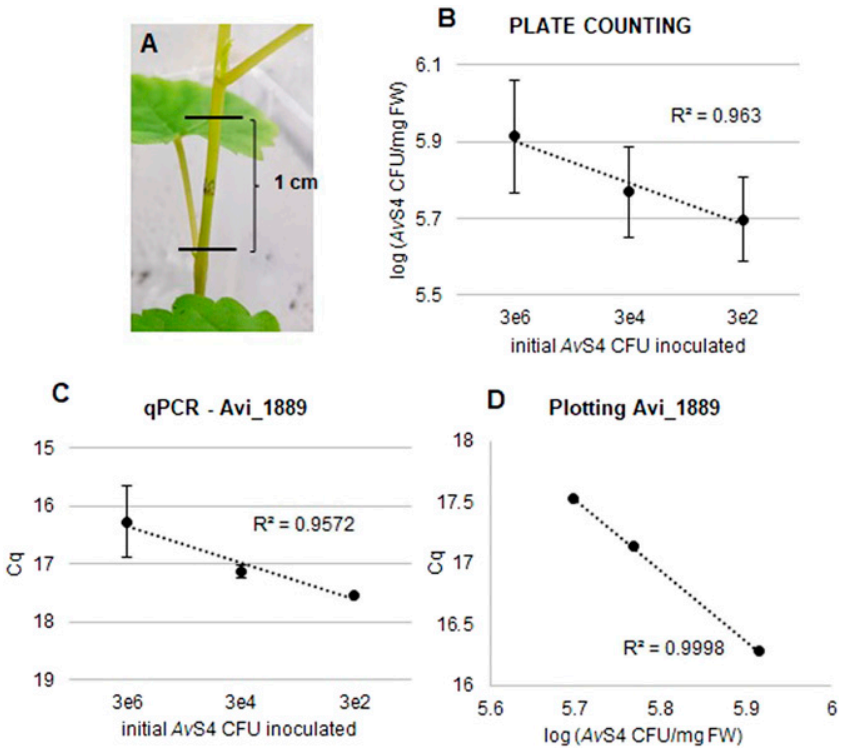

Fig. 4. Comparative analysis of two quantification methods for Allorhizobium vitis strain S4 (AvS4) growth levels at 7 days postinfection (dpi) from different initial numbers of CFU inoculated. A, A 1-cm stem segment collected for plate counting or quantitative real-time PCR (qPCR). Bacterial levels in planta were quantified by B, plate counting and $\mathbf{C}$, qPCR methods with primer Avi_1889. Data represent means \pm SDs of three replicates of three stem segments $(n=9)$ for plate counting and two replicates of three stem segments $(n=6)$ for qPCR. D, Results of the two assays are plotted against each other. Correlation coefficients $\left(R^{2}\right)$ are indicated. These results represent one of two independent biological repetitions. $\mathrm{FW}=$ fresh weight and $\mathrm{Cq}=$ quantification cycle. vitis strains tested. However, one should keep in mind that these results gave just a very primary overview of the specificity of these primers toward Allorhizobium vitis strains and other bacterial species. Because of the low numbers of strains involved and primer-template mismatch, these results are only applicable within Allorhizobium vitis strains tested. For other purposes such as indexing samples from vineyards with the presence of more diverse microorganisms, further investigation must be realized. In the same way, the primers developed here cannot be used to diagnose the presence of Allorhizobium vitis in grapevine crown gall or for epidemiological studies so far.

In qPCR, primer sensitivity is expressed as the limit of detection, which is the concentration of the template that can be detected with 95\% certainty (Bustin et al. 2009). Our results showed that five primer pairs could quantify different levels of $A v \mathrm{~S} 4$ gDNA until $0.5 \mathrm{pg}$. These results are comparable to those obtained by Abdullah et al. (2018), who were able to detect until $0.5 \mathrm{pg}$ of fungal DNA in wheat by qPCR. Even in the presence of grapevine DNA matrix, their activity was not influenced (Fig. 2), indicating that these primer pairs can be used for in planta quantification. By testing a series of Allorhizobium vitis $\mathrm{S} 4$ concentrations ranging from $10^{5}$ to $10^{-1} \mathrm{CFU} / \mathrm{mg}$ $\mathrm{FW}$, we showed that the lowest limit of detection of all primers in planta was $10^{2} \mathrm{CFU} / \mathrm{mg} \mathrm{FW}$. We also tested different initial bacterial titers $\left(3.10^{2}, 3.10^{4}\right.$, and $\left.3.10^{6} \mathrm{CFU}\right)$ for shoot inoculation. Our results confirmed the ability of qPCR to monitor the bacterial population level in planta from a low to high level. Moreover, the comparison of the two methods showed a good correlation $\left(R^{2}>0.97\right)$ at different levels of infection, from the early stage (at $1 \mathrm{dpi}$ ) until tumor development (at $21 \mathrm{dpi}$ ). However, we observed an overestimation of the $A \nu \mathrm{S} 4$ population by $\mathrm{qPCR}$, owing to amplification of nondegraded DNA material from dead bacterial cells as described previously (Ross and Somssich 2016). Our DNA-based method is not as sensitive as MCH (Johnson et al. 2013) or ddPCR (Voegel and Nelson

A
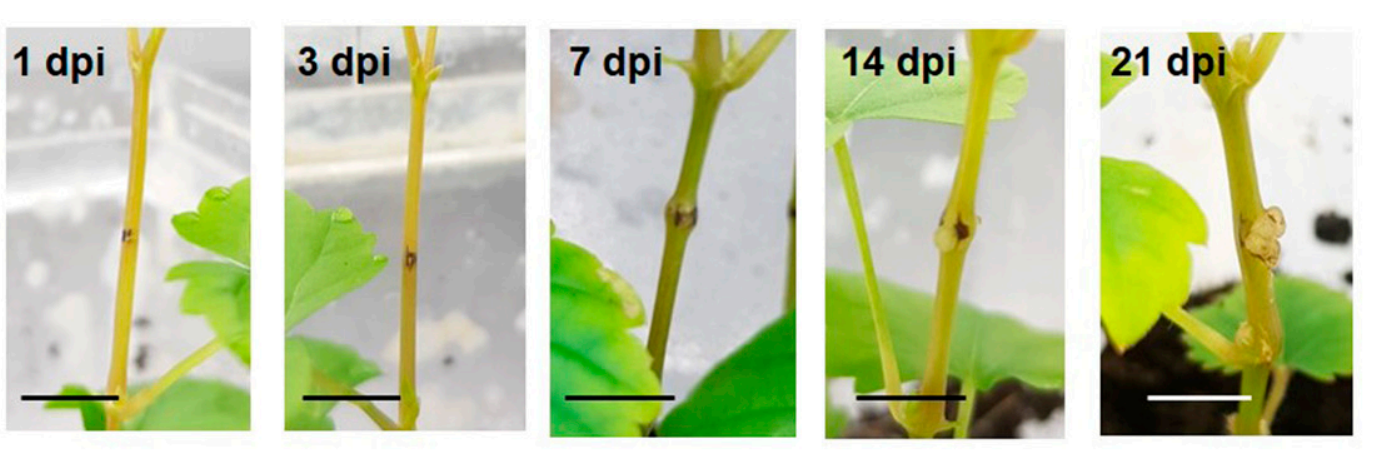

B

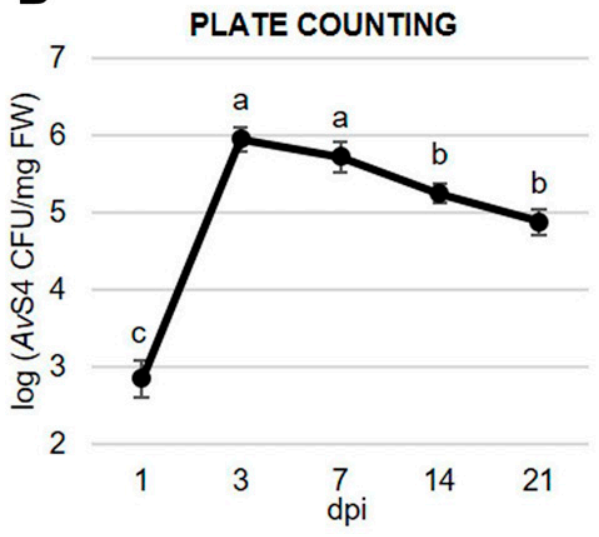

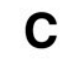

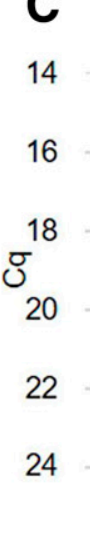

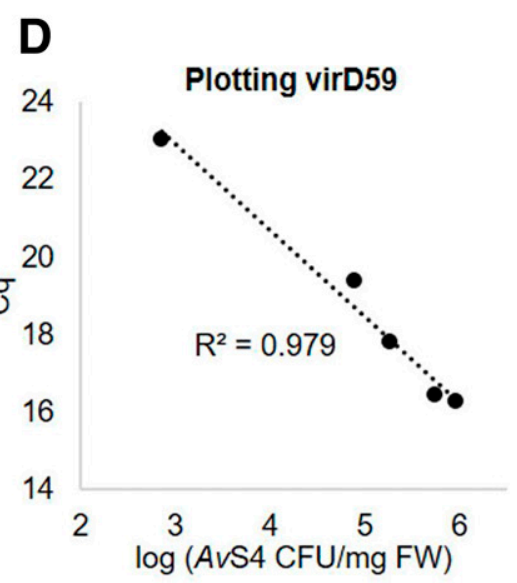

Fig. 5. Comparative analysis of two quantification methods for Allorhizobium vitis strain S4 (AvS4) growth levels over the time course of infection. A, Tumor growth over 21 days of the experiment. Bars $=5 \mathrm{~mm}$. Bacterial growth was determined by $\mathbf{B}$, the plate counting method and $\mathbf{C}$, quantitative real-time $P C R$ with primer virD59. Data represent means \pm SD of three replicates of three stem segments $(n=9)$ for both methods. $\mathbf{D}$, Results of the two assays are plotted against each other. Correlation coefficients $\left(R^{2}\right)$ are indicated. Data with the same letters have no significant differences according to the Tukey test at $P<0.05$. These results represent one of three independent biological repetitions. dpi $=$ days postinfection and $\mathrm{Cq}=$ quantification cycle. 
2018) used for in planta detection. Nevertheless, it is less complicated than $\mathrm{MCH}$, which needs a step to enrich the pathogen DNA, and it is more popular than ddPCR so far. Moreover, since our method gave robust, repetitive, and high similarity with plate counting assays, it can replace the latter method in basic research (e.g., colonization profile). The qPCR method allows temporary storage of samples and, hence, analysis at various time points. A large number of samples can be processed simultaneously and results can be achieved within only a few hours.

\section{Conclusion}

In this study, we validated new primer pairs for the use of qPCR as an alternative and highly comparable method to the plate counting assay. The proposed method allows monitoring of Allorhizobium vitis growth in $V$. vinifera shoots before emergence of the first symptoms until full tumor development. Its accuracy, rapidity, flexibility, and specificity over the plate counting assay are undeniable. To go further, the qPCR assay can be applied in fundamental research to study derivative mutants of $A v \mathrm{~S} 4$ or to monitor pathogen bacterial populations in the presence of a biological control agent.

\section{Literature Cited}

Abdullah, A. S., Turo, C., Moffat, C. S., Lopez-Ruiz, F. J., Gibberd, M. R., Hamblin, J., and Zerihun, A. 2018. Real-time PCR for diagnosing and quantifying co-infection by two globally distributed fungal pathogens of wheat. Front. Plant Sci. 9:1086.

Ait Barka, E., Nowak, J., and Clément, C. 2006. Enhancement of chilling resistance of inoculated grapevine plantlets with a plant growth-promoting rhizobacterium, Burkholderia phytofirmans strain PsJN. Appl. Environ. Microbiol. 72:7246-7252.

Argun, N., Momol, M. T., Maden, S., Momol, E. A., Reid, C. L., Çelek, H., and Burr, T. J. 2002. Characterization of Agrobacterium vitis strains isolated from Turkish grape cultivars in the Central Anatolia region. Plant Dis. 86:162-166.

Bini, F., Geider, K., and Bazzi, C. 2008a. Detection of Agrobacterium vitis by PCR using novel virD2 gene-specific primers that discriminate two subgroups. Eur. J. Plant Pathol. 122:403-411.

Bini, F., Kuczmog, A., Putnoky, P., Otten, L., Bazzi, C., Burr, T. J., and Szegedi, E. 2008b. Novel pathogen-specific primers for the detection of Agrobacterium vitis and Agrobacterium tumefaciens. Vitis J. Grapevine Res. 47:181-189.

Brouwer, M., Lievens, B., Van Hemelrijck, W., Van den Ackerveken, G., Cammue, B., and Thomma, B. 2003. Quantification of disease progression of several microbial pathogens on Arabidopsis thaliana using real-time fluorescence PCR. FEMS Microbiol. Lett. 228:241-248.

Burr, T. J., Bazzi, C., Süle, S., and Otten, L. 1998. Crown gall of grape: Biology of Agrobacterium vitis and the development of disease control strategies. Plant Dis. 82:1288-1297.

Burr, T. J., Johnson, K. L., Kaewnum, S., and Szegedi, E. 2017. Detection of Agrobacterium spp. in grapevines. Pages 321-330 in: Detection of plant-pathogenic bacteria in seed and other planting material. M. B. Fatmi, R. R. Walcott, and N. W. Schaad, eds. American Phytopathological Society, Minneapolis, MN.

Burr, T. J., and Katz, B. H. 1983. Isolation of Agrobacterium tumefaciens biovar 3 from grapevine galls and sap, and from vineyard soil. Phytopathology 73:163-165.

Bustin, S. A., Benes, V., Garson, J. A., Hellemans, J., Huggett, J., Kubista, M., Mueller, R., Nolan, T., Pfaffl, M. W., Shipley, G. L., and Vandesompele, J. 2009. The MIQE guidelines: Minimum information for publication of quantitative real-time PCR experiments. Clin. Chem. 55:611-622.

Ferrigo, D., Causin, R., and Raiola, A. 2017. Effect of potential biocontrol agents selected among grapevine endophytes and commercial products on crown gall disease. BioControl 62:821-833.

Gachon, C., and Saindrenan, P. 2004. Real-time PCR monitoring of fungal development in Arabidopsis thaliana infected by Alternaria brassicicola and Botrytis cinerea. Plant Physiol. Biochem. 42:367-371.

Gelvin, S. B. 2017. Integration of Agrobacterium T-DNA into the plant genome. Annu. Rev. Genet. 51:195-217.

Gouy, M., Guindon, S., and Gascuel, O. 2010. SeaView version 4: A multiplatform graphical user interface for sequence alignment and phylogenetic tree building. Mol. Biol. Evol. 27:221-224.

Habbadi, K., Duplay, Q., Chapulliot, D., Kerzaon, I., Benkirane, R., Benbouazza, A., Wisniewski-Dyé, F., Lavire, C., Achbani, E. H., and Vial, L. 2020. Characterization and phylogenetic diversity of Allorhizobium vitis isolated from grapevine in Morocco. J. Appl. Microbiol. 128:828-839.

Hao, L., Kemmenoe, D. J., Orel, D. C., and Burr, T. J. 2018. The impacts of tumorigenic and nontumorigenic Agrobacterium vitis strains on graft strength and growth of grapevines. Plant Dis. 102:375-381.

Johnson, K. L., Cronin, H., Reid, C. L., and Burr, T. J. 2016. Distribution of Agrobacterium vitis in grapevines and its relevance to pathogen elimination. Plant Dis. 100:791-796.

Johnson, K. L., Zheng, D., Kaewnum, S., Reid, C. L., and Burr, T. J. 2013. Development of a magnetic capture hybridization real-time PCR assay for detection of tumorigenic Agrobacterium vitis in grapevines. Phytopathology 103:633-640.
Jung, S. M., Hur, Y. Y., Preece, J. E., Fiehn, O., and Kim, Y. H. 2016. Profiling of disease-related metabolites in grapevine internode tissues infected with Agrobacterium vitis. Plant Pathol. J. 32:489-499.

Kaewnum, S., Zheng, D., Reid, C. L., Johnson, K. L., Gee, J. C., and Burr, T. J. 2013 A host-specific biological control of grape crown gall by Agrobacterium vitis strain F2/5: Its regulation and population dynamics. Phytopathology 103:427-435.

Kawaguchi, A. 2014. Reduction in pathogen populations at grapevine wound sites is associated with the mechanism underlying the biological control of crown gall by Rhizobium vitis strain ARK-1. Microbes Environ. 29:296-302

Keane, P. J., Kerr, A., and New, P. B. 1970. Crown gall of stone fruit II. Identification and nomenclature of Agrobacterium isolates. Aust. J. Biol. Sci. 23:585-596.

King, E. O., Ward, M. K., and Raney, D. E. 1954. Two simple media for the demonstration of pyocyanin and fluorescin. J. Lab. Clin. Med. 44:301-307.

Kuzmanović, N., Ivanović, M., Prokić, A., Gašić, K., Zlatković, N., and Obradović, A. 2014. Characterization and phylogenetic diversity of Agrobacterium vitis from Serbia based on sequence analysis of $16 \mathrm{~S}-23 \mathrm{~S}$ rRNA internal transcribed spacer (ITS) region. Eur. J. Plant Pathol. 140:757-768.

Kuzmanović, N., Puławska, J., Hao, L., and Burr, T. J. 2018. The ecology of Agrobacterium vitis and management of crown gall disease in vineyards. Curr. Top. Microbiol. Immunol. 418:15-53.

Lehoczky, J. 1968. Spread of Agrobacterium tumefaciens in the vessels of the grapevine, after natural infection. J. Phytopathol. 63:239-246.

Li, Z. T., Dhekney, S. A., Dutt, M., and Gray, D. J. 2008. An improved protocol for Agrobacterium-mediated transformation of grapevine (Vitis vinifera L.). Plant Cell Tissue Organ Cult. 93:311-321

Llorente, B., Bravo-Almonacid, F., Cvitanich, C., Orlowska, E., Torres, H. N., Flawiá, M. M., and Alonso, G. D. 2010. A quantitative real-time PCR method for in planta monitoring of Phytophthora infestans growth. Lett Appl. Microbiol. 51:603-610.

Martin, R. R., James, D., and Lévesque, C. A. 2000. Impacts of molecular diagnostic technologies on plant disease management. Annu. Rev. Phytopathol. 38:207-239.

Mousavi, S. A., Österman, J., Wahlberg, N., Nesme, X., Lavire, C., Vial, L. Paulin, L., de Lajudie, P., and Lindström, K. 2014. Phylogeny of the Rhizobium-Allorhizobium-Agrobacterium clade supports the delineation of Neorhizobium gen. nov. Syst. Appl. Microbiol. 37:208-215.

Mousavi, S. A., Willems, A., Nesme, X., de Lajudie, P., and Lindström, K. 2015 Revised phylogeny of Rhizobiaceae: Proposal of the delineation of Pararhizobium gen. nov., and 13 new species combinations. Syst. Appl. Microbiol. 38:84-90.

Nester, E. W. 2015. Agrobacterium: Nature's genetic engineer. Front. Plant Sci. 5:730

Ophel, K., and Kerr, A. 1990. Agrobacterium vitis sp. nov. for strains of Agrobacterium biovar 3 from grapevines. Int. J. Syst. Bacteriol. 40:236-241.

Orel, D. C., Reid, C. L., Fuchs, M., and Burr, T. J. 2017. Identifying environmental sources of Agrobacterium vitis in vineyards and wild grapevines. Am. J. Enol. Vitic. 68:213-217.

Ross, A., and Somssich, I. E. 2016. A DNA-based real-time PCR assay for robust growth quantification of the bacterial pathogen Pseudomonas syringae on Arabidopsis thaliana. Plant Methods 12:48.

Schroth, M. N., McCain, A. H., Foott, J. H., and Huisman, O. C. 1988. Reduction in yield and vigor of grapevine caused by crown gall disease. Plant Dis. 72 : 241-246.

Schroth, M. N., Weinhold, A. R., McCain, A. H., Hildebrand, D. C., and Ross, N 1971. Biology and control of Agrobacterium tumefaciens. Hilgardia 40:537-552.

Schulz, T. F., Lorenz, D., Eichhorn, K. W., and Otten, L. 1993. Amplification of different marker sequences for identification of Agrobacterium vitis strains. Vitis J. Grapevine Res. 32:179-182.

Slater, S. C., Goldman, B. S., Goodner, B., Setubal, J. C., Farrand, S. K., Nester, E. W., Burr, T. J., Banta, L., Dickerman, A. W., Paulsen, I., and Otten, L. 2009. Genome sequences of three Agrobacterium biovars help elucidate the evolution of multichromosome genomes in bacteria. J. Bacteriol. 191:2501-2511.

Spiers, A. G. 1979. Isolation and characterisation of Agrobacterium species. N. Z. J. Agric. Res. 22:631-639.

Stover, E. W., Swartz, H. J., and Burr, T. J. 1997. Endophytic Agrobacterium in crown gall-resistant and -susceptible Vitis genotypes. Vitis 36:21-26.

Süle, S., Lehoczky, J., Jenser, G., Nagy, P., and Burr, T. J. 1995. Infection of grapevine roots by Agrobacterium vitis and Meloidogyne hapla. J. Phytopathol. 143:169-171.

Szegedi, E., and Bottka, S. 2002. Detection of Agrobacterium vitis by polymerase chain reaction in grapevine bleeding sap after isolation on a semiselective medium. Vitis 41:37-42.

Szegedi, E., Czakó, M., Otten, L., and Koncz, C. S. 1988. Opines in crown gal tumours induced by biotype 3 isolates of Agrobacterium tumefaciens. Physiol. Mol. Plant Pathol. 32:237-247.

Voegel, T. M., and Nelson, L. M. 2018. Quantification of Agrobacterium vitis from grapevine nursery stock and vineyard soil using droplet digital PCR. Plant Dis. 102:2136-2141

Vogel, A. M., and Das, A. 1992. The Agrobacterium tumefaciens virD3 gene is not essential for tumorigenicity on plants. J. Bacteriol. 174:5161-5164.

Weßling, R., and Panstruga, R. 2012. Rapid quantification of plant-powdery mildew interactions by qPCR and conidiospore counts. Plant Methods 8:35.

Ye, J., Coulouris, G., Zaretskaya, I., Cutcutache, I., Rozen, S., and Madden, T. L. 2012. Primer-BLAST: A tool to design target-specific primers for polymerase chain reaction. BMC Bioinformatics 13:134 